\title{
Mindful living: Character strengths interventions as pathways for the five mindfulness trainings
}

\author{
Ryan M. Niemiec
}

\begin{abstract}
The "Five Mindfulness Trainings" of Thich Nhat Hanh (1993) have been pursued and practiced by countless individuals over the years. The core of the trainings is mindful living, in which individuals apply heightened awareness to their relationships, health behaviors, and activities of daily life, while considering the impact of these on society. The VIA character strengths, found to be universally valued and endorsed across cultures and nations, can serve as pathways to pursue these mindfulness trainings. Positive psychology interventions designed to enhance the synergy between character strengths and the mindfulness trainings are offered.
\end{abstract}

Key words: Character strengths, mindfulness, Thich Nhat Hanh, mindful living, positive psychology interventions

\section{$80 \cdot 08$}

My actions are my only true belongings.

-Thich Nhat Hanh

\section{Introduction}

The wise, humble, and zestful monk, Thich Nhat Hanh, has inspired countless individuals over the years with his teachings on mindfulness, peace, and compassion (Kabat-Zinn, 2005). Many of his teachings are aligned with and parallel findings and ideas in positive psychology.

One of his popular teachings is the "Five Mindfulness Trainings", which are a modern-day re-formulation of some of the Buddha's core teachings. The Five Mindfulness Trainings are Reverence for Life, True Happiness, True Love, Loving Speech and Deep Listening, and Nourishment and Healing (Nhat Hanh, 1993; Nhat Hanh \& Cheung, 2010), and provide pathways to a life of greater joy, engagement, and meaning. Indeed, these are not only a recipe for mindful living but present a striking vision for a global ethic. The potential impact of the trainings on individuals, relationships, and society is significant. Consider a world in which more people, groups, and organizations bring careful intentionality to what they are doing, listen to one another with more compassion, and reflect more deeply on the impact of healthy and unhealthy choices on oneself and on others. For a full commentary on an earlier version of the trainings, see Nhat Hanh (1993), or for the most recent revision of the trainings (the version discussed in this article), see Nhat Hanh \& Cheung (2010). ${ }^{1}$

${ }^{1}$ Also available in brief online at: http://www.plumvillage.org/mindfulness-trainings/3-the-five-mindfulness-trainings.html. 
Thich Nhat Hanh makes it clear that each of the Five Mindfulness Trainings are ideas to work toward (i.e., trainings) rather than final ideals to achieve or commandments one must or should follow. He offers an apt metaphor of the North Star, which can help to guide or direct individuals in a particular direction though one can never make it to the destination. The individual variance for how a person might go about the journey of practicing each training is significant; some individuals take a formal, systematic approach, delving into the trainings oneby-one in their personal study or through study with their mindfulness community, while others approach the trainings more informally, focusing on where their particular needs and interests are at present.

But, what are the mechanisms that make the journey with the mindfulness trainings possible? What ingredients in ourselves can we turn to in order to manifest mindfulness and the Five Mindfulness Trainings more strongly? One answer lies in our strengths of character.

This paper draws some important connections between character strengths and the mindfulness trainings and offers practical suggestions rooted in the latest science that will help deepen one's understanding and practice of mindfulness.

\section{Connecting character strengths with mindfulness}

About a decade ago, 55 scientists began an ambitious project that analyzed and studied the best thinking on human goodness, virtue, and strength across time, culture, religions, and nations. They reviewed hundreds of philosophical, religious, and various classic works on virtue that have been written over the last 2,500 years. The result of this three-year project-rooted in the science of positive psychology - was a universal classification of virtues and strengths of character (Peterson \& Seligman, 2004). This VIA Classification (see Figure 1) of six virtues and 24 character strengths has become a "common language" for people around the world as it describes the psychological ingredients of what is best in human beings. These character strengths are viewed as "who we are" at our core-our essence.

In the original work describing the VIA Classification (Peterson \& Seligman, 2004), the scientists allude to an immediate connection between character strengths and the Five Mindfulness Trainings. They suggest that the first (Reverence for Life), second (True Happiness, and fourth (Loving Speech and Deep Listening) mindfulness trainings connect closely with the humanity and justice strengths, and that the third (True Love) and fifth (Nourishment and Healing) mindfulness trainings connect closely with the temperance and courage strengths.

Other researchers have defined the concept of mindfulness as containing two important ingredients that can be understood in terms of these character strengths (Bishop et al., 2004; Coffey, Hartman, \& Fredrickson, 2010): One is the strength of self-regulation in that when we are mindful we are taking control of our attention, regulating it into the present moment; the other is the strength of curiosity in that when we are practicing mindfulness, our approach or attitude to the present moment is to be curious, open, and accepting of whatever is present (Bishop et al., 2004). Indeed the strength of curiosity functions to open us up to possibilities in the present moment and to help us move toward and mindfully approach all of the vicissitudes of life-the positive and beautiful as well as the challenging and upsetting (Kashdan, 2009). 
Figure 1. VIA Classification

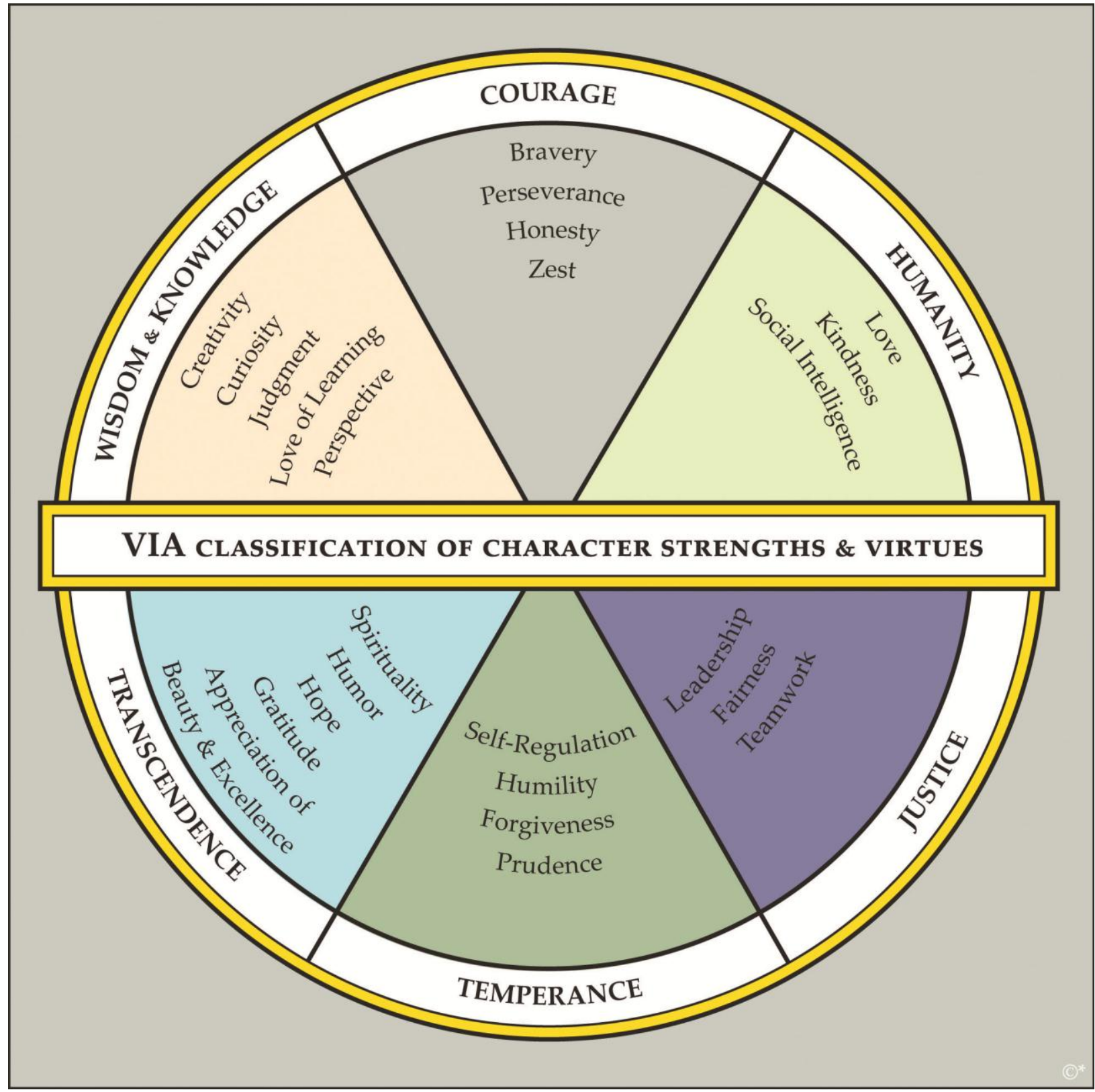

Note: VIA Classification is copyrighted material of VIA Institute on Character, 2004. Used with Permission. www.viacharacter.org. Furthermore, duplication of this image requires permission from the VIA institute, and a reference to this article as the source of the image.

It appears that mindfulness and character strengths can positively impact one another. Increased amount of time spent using strengths has been found to correlate significantly $\left(.26^{* *}\right)$ with mindfulness (Jarden, Jose, Kashdan, Simpson, McLachlan, \& Mackenzie, 2012). Mindfulness can help an individual express their character strengths in a balanced way that is sensitive to the context and circumstance they are in (Niemiec, Rashid, \& Spinella, in press). On the other hand, character strengths such as curiosity can help bolster a person's mindfulness practice, helping them overcome obstacles and barriers in maintaining a regular practice (Niemiec, Rashid, \& Spinella, in press). 


\section{Thich Nhat Hanh: A true positive psychologist}

Many of the teachings and publications of Thich Nhat Hanh connect closely with principles of positive psychology and with principles relating to character strengths.

\subsection{Internal conditions for happiness}

One of the key themes of the mindfulness trainings is that individual wellbeing relies more upon internal conditions such as compassion, joy, and the pursuit of community, positive relationships, and personal growth than external conditions such as money, status, and image. As Thich Nhat Hanh has often noted, we already have more than enough conditions to be happy (Nhat Hanh, 2009). He is referring to those internal conditions that we can turn to within ourselves in any present moment. This is consistent with happiness research findings that there are better outcomes for intrinsic goals (e.g., I want to have a closer relationship with my spouse) over extrinsic goals (e.g., I want to make more money; Kasser, 2006). Character strengths can be viewed as many of those important "internal conditions" that are already present in everyone and that are pivotal for setting intrinsic-oriented goals.

\subsection{The middle way}

Echoing the Buddha, who spoke of practicing "the Way," Thich Nhat Hanh (1998) emphasizes the application of diligence among extremes such as those of austerity and sensual pleasure, and emphasizes finding balance in one's practice of the five mindfulness trainings rather than forcing oneself to be "perfect" or rigid in the application. Similarly, Aristotle (2000) articulated this as the "golden mean," the balance between excess and deficiency with one's life activities of working, learning, playing, loving, and serving; this balance then leads to the ultimate goal of personal happiness. In strengths psychology, this can be referred to as finding a balance between overuse and underuse of character strengths (Biswas-Diener, Kashdan, \& Minhas, 2011; Grant \& Schwartz, 2011; Linley, 2008), e.g., for bravery, the middle way is the balance between recklessness and cowardice, while for curiosity it is the balance between nosiness and lack of interest.

\subsection{Watering the seeds}

All 24 character strengths matter. This important principle emphasizes how each strength is a capacity in individuals that can be developed with practice. Thich Nhat Hanh (1998) describes the practice of "watering the seeds" of virtue and those wholesome, interior elements rather than unwholesome seeds of suffering and violence (e.g., watering kindness rather than anger). This is likened to the nourishing of any of the 24 character strengths' "seeds" through deliberate intervention and mindful care. While all strengths matter, it might be that "watering" one's highest strengths elicits the greatest benefit. Research on signature strengths - those most authentic, natural, and energizing to the person - has revealed a strong connection with happiness (Linley, Nielsen, Gillett, \& Biswas-Diener, 2010; Littman-Ovadia \& Davidovitch, 2010; Littman-Ovadia \& Steger, 2010; Madden, Green, \& Grant, 2011; Mitchell, Stanimirovic, Klein, \& Vella-Brodrick, 2009; Mongrain \& Anselmo, 2009; Peterson \& Peterson, 2008; Rust, Diessner, \& Reade, 2009; Seligman, Steen, Park, \& Peterson, 2005). 


\subsection{Interbeing}

Thich Nhat Hanh (1998) offers the word "interbeing" to refer to the mutual relationship and interconnection of things. Also described as "interdependent co-arising," this teaching is that causes and effects co-arise and

[...] ]everything is a result of multiple causes and conditions. The egg is in the chicken, and the chicken is in the egg. Chicken and egg arise in mutual dependence. Neither is independent. (Nhat Hanh, 1998, p. 221)

He offers the example of how we can gaze at a tree and see how a cloud, the rain, and the soil are part of the tree, because without the cloud, rain, and soil, there wouldn't be a tree to grow. Thus, there is "interbeing" among these elements. This teaching can be applied to the 24 character strengths in that all of the character strengths are linked with one another; the strengths do not function in isolation or independent of one another - the expression of one of these virtuous qualities likely affects the others to some degree. For example, when a person is offering deep forgiveness to another, they are also expressing perspective, bravery, kindness, spirituality, humility, and so forth. Scientists have performed intercorrelation matrices on the VIA character strengths and naturally each strength correlates to some degree with the others. When focusing on a character strength in order to practice a mindfulness training, it is likely other character strengths are deployed or at least impacted.

\section{Using strengths to promote mindful living}

After a person becomes more aware of their character strengths, how might they use them to deepen their experience of the Five Mindfulness Trainings? Here are some practical ways that character strengths might impact, inform, and enhance one's use of each mindfulness training. An attempt is made to offer science-based suggestions, but each should be viewed as a preliminary idea that warrants further scientific inquiry, especially in terms of its potential impact on the mindfulness training; each intervention is offered to help encourage and support the mindfulness practice of individuals and communities.

\subsection{Reverence for Life}

The first mindfulness training, Reverence for Life, begins:

Aware of the suffering caused by the destruction of life, I am committed to cultivating the insight of interbeing and compassion and to learning ways to protect the lives of people, animals, plants and minerals (Nhat Hanh \& Cheung, 2010, p. 210).

It also encourages the cultivation of openness, non-discrimination, and nonattachment to views. This training directly invites individuals to increase their kindness/compassion strength to a level that moves the focus on oneself to a focus on others, namely all living beings. The strength of fairness appears to be an underlying principle for this training. Those high in this character strength navigate their lives through principles of equity and justice for all. Such an approach is the basis for a healthy, global community, which this mindfulness training emphasizes.

\subsubsection{How might character strengths help in the practice of this training?}

- When one finds oneself gravitating toward dualistic or exclusiveness in thinking, call upon the judgment/critical thinking strength to consider multiple viewpoints (Tetlock, 
1986). Combining this with the fairness strength can help one see all sides of an issue, and to find a sense of balance and a common, middle ground.

- Use the bravery strength to speak against acts of killing in the world, even those that appear benign such as deliberately stepping on a spider on the sidewalk. To mindlessly "squash" any form of life is to subtly rehearse a cognitive and behavior routine of apathy and disregard for living beings.

- Build the appreciation of beauty strength by training oneself to see beauty wherever one looks; keep a "beauty $\log$ " in which one regularly writes about the wonders of the life and beauty of plants, animals, and even the moral acts of beauty witnessed in others (Diessner, Rust, Solom, Frost, \& Parsons, 2006).

\subsection{True Happiness}

The second mindfulness training, True Happiness, begins:

Aware of the suffering caused by exploitation, social injustice, stealing, and oppression, I am committed to practicing generosity in my thinking, speaking, and acting (Nhat Hanh \& Cheung, 2010, p. 210).

It also encourages the individual to see a connection between one's own happiness and suffering, and the happiness and suffering of others. This training emphasizes a focus on generosity and understanding, with less of a focus on external conditions that are superficial in nature, such as fame, wealth, and material possessions. While the thrust of this training speaks against straightforward, anti-societal behaviors such as stealing, oppression or exploitation of the less fortunate, there are subtle examples of this training to examine. For example, people can steal someone's idea by not giving due credit, upstage someone at a business meeting ("stealing someone's thunder"), or steal someone's time by monopolizing a conversation. The impact of inaction-not helping those in real need and those being oppressed in societydeserves deep contemplation in the context of this training.

\subsubsection{How might you use character strengths to practice this training?}

- The simplest answer is: Give. Giving, being generous, and volunteering are core components of the kindness character strength and when expressed have a positive impact on both the giver and the receiver (Luks, 1991; Post, 2005).

- Be grateful. The research surrounding the benefits of expressing the strength of gratitude is mounting. Research shows that people who are grateful are often more communal, altruistic, happy, and less materialistic. Gratitude also engenders a deep sense of appreciation for what one already has in life (Emmons \& McCullough, 2003; Seligman, Steen, Park, \& Peterson, 2005).

- Teamwork and leadership: There are important benefits to taking a "we" approach as to an "I" approach (Son, Jackson, Grove, \& Feltz, 2011), and indeed these two justiceoriented, civic strengths focus on what is best for the larger group. One can consider how these play a role on a small scale with a small project in one's life, and then shift the focus to a wider audience.

\subsection{True Love}

The third mindfulness training, True Love, begins:

Aware of the suffering caused by sexual misconduct, I am committed to cultivating responsibility and learning ways to protect the safety and integrity of 
individuals, couples, families, and society... cultivating loving kindness, compassion, joy and inclusiveness - which are the four basic elements of true love (Nhat Hanh \& Cheung, 2010, p. 211).

The training calls for a mindful sexuality and a strong degree of commitment in our relationships. Another aspect of this training involves protecting children from sexual abuse and whenever possible keeping the institution of "family" together. Here, it is the perspective/wisdom strength that needs to be called forth to allow for the wider view of life and what is truly important. This involves calling forth both strengths of the heart and strengths of the mind in order to overcome desire, cravings, and drives that can lead to rash choices, superficial outcomes, and destruction of relationships.

\subsubsection{How might you use character strengths to practice this training?}

- Build the strength of prudence. Prudence, sometimes called "cautious wisdom," is an important strength to use when it comes to sexual desire. If one is uncertain about a relationship, one should use prudence to conduct a cost-benefit analysis. What are the costs and benefits of the action that is about to be taken? What are the costs and benefits of not taking the action? (Rollnick \& Miller, 1995). In addition, one might use one's heart-oriented strengths (e.g., curiosity) by asking for others' feedback about one's relationship partner and listening closely without judgment to the feedback.

- When in doubt a general guideline is to be honest and authentic in all relationships. Integrity involves allowing who one is at the core to be aligned with what one expresses to others at work, home, and socially. This strength of honesty/integrity usually requires the strength of bravery - as in being brave enough to share who one is - to face any sexual improprieties in one's life (past or current), and/or to speak against any sexual misbehaviors witnessed against children, adolescents, or adults.

- Combat mindlessness with perspective and social intelligence. It's easy to fall into automatic pilot in our relationships (Segal, Williams, \& Teasdale, 2002) with close others, therefore, it is important to periodically check in on ourselves with questions such as: How might I commit more in my relationships? Is there anything I've been avoiding with anyone? Applying this requires attending to the "golden mean" of strengths and virtues - using strengths at the right time, to the right degree, in the right situation. This requires a bigger picture perspective and the social intelligence strength - being aware of one's own feelings, others' feelings, and the social nuances of the context one is in (Schwartz \& Sharpe, 2006).

- Embed a lovingkindness meditation into a current mindfulness practice. Involving imaging, loving statements, and positive reminiscing, lovingkindness practice expands love and improves health on a personal level (Cohn \& Fredrickson, 2010; Salzberg, 1997), but it is likely there are further benefits extending to the fostering of healthy relationships.

\subsection{Loving Speech and Deep Listening}

The fourth mindfulness training, Loving Speech and Deep Listening, begins:

Aware of the suffering caused by unmindful speech and the inability to listen to others, I am committed to cultivating loving speech and compassionate listening in order to relieve suffering and to promote reconciliation and peace (Nhat Hanh \& Cheung, 2010, p. 211). 
This training invites a focus upon the practice of mindful speech and deep listening. No doubt compassion/kindness is a core strength used in these practices. Curiosity is also important as research has found that being curious in social relationships can lead to stronger, more intimate relationships than those who don't take an open, curious approach (Kashdan, McKnight, Fincham, \& Rose, 2011).

\subsubsection{How might you use character strengths to practice this training?}

- Learn to offer active-constructive responses when someone shares good news (Gable, Reis, Impett, \& Asher, 2004). This involves a mix of the strengths of love (providing warmth and genuineness in the response), social intelligence (detecting the person is sharing something that's important to them), and humility and self-regulation (to not have to share your good news too but to help the person who is sharing to savor in the moment). Research has shown this type of responding is important for successful relationships and it is likely to improve mindful speech and deep listening.

- Learn to empathize when someone shares bad news or appears to be suffering (Batson, Chang, Orr, \& Rowland, 2002). Listen with eyes and ears of compassion: What might they be feeling? As one takes notice of what the other person is feeling, can their emotions be felt as well? If so, one can share this. Compassion is to suffer with and to be with the person; it is a type of kindness strength that can be offered to loved ones. While listening, one might ask oneself, "Where is the person coming from? What are they saying or trying to say? What is the essence or core message that they are expressing?" For example, a woman yelling at her husband for being late for a dinner date might be feeling - at her core-disrespected and unloved.

- Practice forgiveness when someone close brings one harm. This does not mean to forget their action, nor to condone what they have done, but to let go of one's own suffering. Research reveals that writing about the personal benefits that have resulted from someone's harmful actions leads to greater forgiveness than writing about the trauma of the harmful act (McCullough, Root, \& Cohen, 2006). The strength of forgiveness is closely linked and impacted by having an other-focused compassion in which one listens deeply to the suffering of others and considers the humanity of the offender (Witvliet, Knoll, Hinman, \& DeYoung, 2010; Witvliet, DeYoung, Hofelich, \& DeYoung, 2011).

\subsection{Nourishment and Healing}

The fifth mindfulness training, Nourishment and Healing, begins:

Aware of the suffering caused by unmindful consumption, I am committed to cultivating good health, both physical and mental, for myself, my family, and my society by practicing mindful eating, drinking, and consuming. (Nhat Hanh \& Cheung, 2010, p. 212)

Consuming goes beyond food and drink to the consumption of websites, movies, television programs, video games, books, magazines, and conversations. This training is about taking care of one's whole self and being a mindful consumer. Core to this training are the strengths of selfregulation and prudence. Embedded in this mindful practice is the strength of perseverance, as the practice of not consuming alcohol or violent media images/messages is not just something to be done once or twice but is an ongoing practice requiring perseverance. This strength 
involves overcoming obstacles that emerge and reframing them as growth opportunities (Dweck, 2006).

\subsubsection{How might you use character strengths to practice this training?}

- Self-monitor daily healthy and unhealthy eating and drinking habits. Create a detailed food and drink log. This self-regulation strategy is a key health habit. Interestingly, research has found that the regular practice and improvement of one behavior involving self-regulation automatically improves other behaviors involving this strength. For example, improving one's self-regulation with food improves one's selfregulation in other areas, such as exercise, mindfulness, or even managing finances (Baumeister, Matthew, DeWall, \& Oaten, 2006).

- Track the non-edible products that one's consciousness consumes. Set a watch alarm to beep one time per hour; when it beeps, take notice of what one's consciousness is taking in - a television commercial, a radio program, a website, a video game, a personal conversation, a book, etc. Ask oneself: Is this product or experience right now having a positive or negative effect on my consciousness? What feelings and thoughts am I experiencing in the present moment in light of this current stimulus? This type of mindful consuming approach involves the use of many character strengths and can be applied to any form of media or art (e.g., Niemiec \& Wedding, 2008).

- Set a health goal that is of personal value to you (Sheldon \& Kasser, 1998). Make the goal something reasonable that you can commit to $100 \%$, even when the going gets tough. The character strengths most associated with goal-setting are hope, perseverance, and prudence. Be prudent to select a goal that is reasonable, be perseverant when the going gets tough, and generate hopeful thoughts about your ability to achieve the goal and to develop alternate pathways to get there, if necessary.

\section{Conclusion}

For many people, a good first step is to learn which character strengths come most naturally and easily to them and which might require more effort to use. The VIA Inventory of Strengths (VIA-IS) is a scientific measurement of strengths that can be taken for free online (VIA Institute, 2012). When one receives the results, some may take an approach of working with their highest-ranking character strengths while others may turn to their lesser strengths and work to enhance them. Yet another approach is to choose one character strength and explore how it interlocks closely with each of the mindfulness trainings. Using kindness/compassion as an example: The first training emphasizes a global kindness, the second emphasizes kindness in the community, the third and fourth narrow the focus to interpersonal and intimate relationships, and the fifth brings the opportunity to the individual to focus on self-kindness. As alluded to earlier, the mindfulness trainings "inter-are" (Nhat Hanh, 1993) - to use one strength such as kindness with one mindfulness training is likely to impact and boost awareness and growth of the other four trainings.

For researchers, there is a lot of territory to explore on this synergy between mindfulness and character strengths, especially within the light of the Five Mindfulness Trainings. One area is the study of these trainings among experienced mindfulness practitioners in communities (meditation sanghas). There are hundreds of communities that pursue these trainings in the tradition of Thich Nhat Hanh and further evaluating the variables and ingredients of these practices and their outcomes relative to the general public would be informative. 
For practitioners, this paper outlines a number of practical strategies that can be used to enhance both character strengths and the mindfulness elements pertaining to each training. Practitioners might review the mindfulness trainings with their clients and have discussions with them as to where the client is strong and doing well, as well as those that the client is struggling with. The strategies that follow can act as a starting point for discussion or can be devised as a homework exercise for clients to advance their knowledge and practice of the given training.

The suggestions offered here are merely the tip of an iceberg. While each of these suggestions has a base in science, they are all merely possibilities one might take in the direction of mindfulness and mindful living. Many of the best ideas for how to use one's strengths to enhance mindfulness will come directly from the individual. Each individual has a unique constellation of character strengths and therefore should spend time exploring how they might bring the trainings closer to their hearts and minds, and integrate them deeply with who they are.

As individuals cultivate their character strengths' "seeds" to work toward the Five Mindfulness Trainings, many will find this brings benefit to their family, to relationships, and to the larger community. That is something that really matters.

\section{Authors}

Ryan M. Niemiec

ryan@viacharacter.org

\section{Publishing Timeline}

Received 10 December 2011

Accepted 8 February 2012

Published 29 April 2012

\section{References:}

Aristotle. (2000). Nicomachean ethics (R. Crisp, Trans.). Cambridge, England: Cambridge University Press.

Batson, C. D., Chang, J., Orr, R., \& Rowland, J. (2002). Empathy, attitudes, and action: Can feeling for a member of a stigmatized group motivate one to help the group? Personality and Social Psychology Bulletin, 28(2), 1656-1666. http://dx.doi.org/10.1177/014616702237647

Baumeister, R. F., Matthew G., DeWall, C. N., \& Oaten, M. (2006). Self-regulation and personality: How interventions increase regulatory success, and how depletion moderates the effects of traits on behavior. Journal of Personality, 74(6), 1773-1802. http://dx.doi.org/10.1111/j.1467-6494.2006.00428.x

Bishop, S. R., Lau, M., Shapiro, S. L., Carlson, L., Anderson, N. D., Carmody, J., et al. (2004). Mindfulness: A proposed operational definition. Clinical Psychology: Science and Practice, 11, 230-241. http://dx.doi.org/10.1093/clipsy.bph077

Biswas-Diener, R., Kashdan, T. B., \& Minhas, G. (2011). A dynamic approach to psychological strength development and intervention. Journal of Positive Psychology, 6(2), 106-118. http://dx.doi.org/10.1080/17439760.2010.545429

Coffey, K. A., Hartman, M., \& Fredrickson, B. L. (2010). Deconstructing mindfulness and constructing mental health: Understanding mindfulness and its mechanisms of action. Mindfulness, 1(4), 235-253. http://dx.doi.org/10.1007/s12671-010-0033-2

Cohn, M. A., \& Fredrickson, B. L. (2010). In search of durable positive psychology interventions: Predictors and consequences of long-term positive behavior change. Journal of Positive Psychology, 5, 355-366. http://dx.doi.org/10.1080/17439760.2010.508883

Diessner, R., Rust, T., Solom, R., Frost, N., \& Parsons, L. (2006). Beauty and hope: A moral beauty intervention. Journal of Moral Education, 35, 301-317. http://dx.doi.org/10.1080/03057240600874430 
Dweck, C. (2006). Mindset: The new psychology of success. New York: Ballantine Books.

Emmons, R. A., \& McCullough, M. E. (2003). Counting blessings versus burdens: An experimental investigation of gratitude and subjective well-being in daily life. Journal of Personality and Social Psychology, 84, 377-389. http://dx.doi.org/10.1037/0022-3514.84.2.377

Gable, S. L., Reis, H. T., Impett, E. A., \& Asher, E. R. (2004). What do you do when things go right? The intrapersonal and interpersonal benefits of sharing positive events. Journal of Personality and Social Psychology, 87(2), 228-245. http://dx.doi.org/10.1037/0022-3514.87.2.228

Grant, A. M., \& Schwartz, B. (2011). Too much of a good thing: The challenge and opportunity of the inverted u. Perspectives on Psychological Science, 6(1) 61-76. http://dx.doi.org/10.1177/1745691610393523

Jarden, A., Jose, P., Kashdan, T., Simpson, O., McLachlan, K., \& Mackenzie, A. (2012). [International Wellbeing Study]. Unpublished raw data.

Kabat-Zinn, J. (2005). Coming to our senses. New York: Hyperion.

Kashdan, T. (2009). Curious? New York: HarperCollins.

Kashdan, T. B., McKnight, P. E., Fincham, F. D., \& Rose, P. (2011). When curiosity breeds intimacy: Taking advantage of intimacy opportunities and transforming boring conversations. Journal of Personality, 79, 1369-1401. http://dx.doi.org/10.1111/j.1467-6494.2010.00697.x

Kasser, T. (2006). Materialism and its alternatives. In M. Csikszentmihály \& I. S. Csikszentmihály (Eds.), A Life Worth Living: Contributions to Positive Psychology (pp. 200-214). Oxford: Oxford University Press.

Linley, A. (2008). Average to A+: Realising strengths in yourself and others. Coventry. CAPP Press.

Linley, P. A., Nielsen, K. M., Gillett, R., \& Biswas-Diener, R. (2010). Using signature strengths in pursuit of goals: Effects on goal progress, need satisfaction, and well-being, and implications for coaching psychologists. International Coaching Psychology Review, 5(1), 6-15.

Littman-Ovadia, H., \& Davidovitch, N. (2010). Effects of congruence and character-strength deployment on work adjustment and well-being. International Journal of Business and Social Science, 1(3), 138-146.

Littman-Ovadia, H., \& Steger, M. (2010). Character strengths and well-being among volunteers and employees: Toward an integrative model. Journal of Positive Psychology, 5(6), 419-430.

http://dx.doi.org/10.1080/17439760.2010.516765

Luks, A. (1991). The healing power of doing good: The health and spiritual benefits of helping others. New York: Fawcett Columbine.

Madden, W., Green, S., \& Grant, A. M. (2011). A pilot study evaluating strengths-based coaching for primary school students: Enhancing engagement and hope. International Coaching Psychology Review, 6(1), 71-83.

McCullough, M. E., Root, L. M., \& Cohen, A. D. (2006). Writing about the benefits of an interpersonal transgression facilitates forgiveness. Journal of Consulting and Clinical Psychology, 74(5), 887-897. http://dx.doi.org/10.1037/0022-006X.74.5.887

Mitchell, J., Stanimirovic, R., Klein, B., \& Vella-Brodrick, D. (2009). A randomised controlled trial of a self-guided internet intervention promoting well-being. Computers in Human Behavior, 25, 749-760. http://dx.doi.org/10.1016/j.chb.2009.02.003

Mongrain, M., \& Anselmo, T. (2009). Promise of positive interventions: Replication of Seligman et al., 2005. Paper presented at American Psychological Association conference on August 6, 2009.

Nhat Hanh, T. (1993). For a future to be possible: Commentaries on the five mindfulness trainings. Berkeley, CA: Parallax Press.

Nhat Hanh, T. (1998). The heart of the Buddha's teaching. New York: Broadway.

Nhat Hanh, T. (2009). Happiness. Berkeley, CA: Parallax Press.

Nhat Hanh, T., \& Cheung, L. (2010). Savor: Mindful eating, mindful life. New York: HarperCollins.

Niemiec, R. M., \& Wedding, D. (2008). Positive psychology at the movies: Using films to build virtues and character strengths. Cambridge, MA: Hogrefe.

Niemiec, R. M., Rashid, T., \& Spinella, M. (in press). Strong mindfulness: Integrating mindfulness and character strengths. Journal of Mental Health Counseling. 
Peterson, T. D., \& Peterson, E. W. (2008). Stemming the tide of law student depression: What law schools need to learn from the science of positive psychology. Yale Journal of Health Policy, Law, and Ethics, $9(2)$.

Peterson, C., \& Seligman, M. E. P. (2004). Character strengths and virtues: A handbook and classification. New York: Oxford University Press.

Post, S. G. (2005). Altruism, happiness, and health: It's good to be good. International Journal of Behavioral Medicine, 12, 66-77. http://dx.doi.org/10.1207/s15327558ijbm1202 4

Rollnick, S. \& Miller, W. R. (1995). What is motivational interviewing? Behavioural and Cognitive Psychotherapy, 23, 325-334. http://dx.doi.org/10.1017/S135246580001643X

Rust, T., Diessner, R., \& Reade, L. (2009). Strengths only or strengths and relative weaknesses? A preliminary study. Journal of Psychology, 143(5), 465-476. http://dx.doi.org/10.3200/JRL.143.5.465-476

Salzburg, S. (1997). Lovingkindness: The revolutionary art of happiness. Boston: Shambhala.

Schwartz, B., \& Sharpe, K. E. (2006). Practical wisdom: Aristotle meets positive psychology. Journal of Happiness Studies, 7, 377-395. http://dx.doi.org/10.1007/s10902-005-3651-y

Segal, Z. V., Williams, M., \& Teasdale, J. (2002). Mindfulness-based cognitive therapy for depression: A new approach to preventing relapse. New York: Guilford.

Seligman, M. E. P., Steen, T. A., Park, N., \& Peterson, C. (2005). Positive psychology progress: Empirical validation of interventions. American Psychologist, 60, 410-421. http://dx.doi.org/10.1037/0003066X.60.5.410

Sheldon, K.M., \& Kasser, T. (1998). Pursuing personal goals: Skills enable progress but not all progress is beneficial. Personality and Social Psychology Bulletin, 24, 546-557. http://dx.doi.org/10.1177/0146167298245010

Son, V., Jackson, B., Grove, J. R., \& Feltz, D. L. (2011). "I am" versus “we are": Effects of distinctive variants of self-talk on efficacy beliefs and motor performance. Journal of Sports Sciences, 1-8

Tetlock, P. E. (1986). A value pluralism model of ideological reasoning. Journal of Personality and Social Psychology, 50, 819-827. http://dx.doi.org/10.1037/0022-3514.50.4.819

VIA Institute (2012). VIA Inventory of Strengths. www.viasurvey.org

Witvliet, C. V. O., DeYoung, N. J., Hofelich, A. J., \& DeYoung, P. A. (2011). Compassionate reappraisal and emotional suppression as alternatives to offense-focused rumination: Implications for forgiveness and psychophysiological well-being. Journal of Positive Psychology, 6(4), 286-299. http://dx.doi.org/10.1080/17439760.2011.577091

Witvliet, C. V. O., Knoll, R. W., Hinman, N. G., \& DeYoung, P. A. (2010). Compassion-focused reappraisal, benefit-focused reappraisal, and rumination after an interpersonal offense: Emotionregulation implications for subjective emotion, linguistic responses, and physiology. Journal of Positive Psychology, 5(3), 226-242. http://dx.doi.org/10.1080/17439761003790997 